\title{
Abrasiveness of Conventional and Specific Denture-Cleansing Dentifrices
}

\author{
Danilo Balero SORGINI \\ Claudia Helena da SILVA-LOVATO \\ Raphael Freitas de SOUZA \\ Letícia Resende DAVI \\ Helena de Freitas Oliveira PARANHOS \\ Department of Dental Materials and Prosthodontics, Ribeirão Preto Dental School, \\ USP - University of São Paulo, Ribeirão Preto, SP, Brasil
}

\begin{abstract}
This study analyzed the weight loss and surface roughness caused in Plexiglass specimens by conventional dentifrices (Sorriso, Colgate and Close Up) and specific dentifrices used for cleaning of dentures (Corega and Dentu Creme). Plexiglass specimens were divided into 6 groups $(\mathrm{n}=6)$ including: a control (distilled water - DW) and experimental groups. Brushing was performed in a toothbrushing machine with a soft brush and a dentifrice suspension and DW according to different brushing times (50, 100, 200 and 250 min - 18,000, 36,000, 72,000 and 90,000 cycles, respectively, calculated to correspond to 1, 2, 4 and 5 years of regular brushing). The results of weight loss and surface roughness were analyzed by ANOVA and Tukey's test at 5\% significance level. In all tested times, the effect of DW was insignificant. Dentifrices differed significantly from DW in the initial period. Corega dentifrice caused greater mass loss in all studied times, followed by Close Up. Dentifrices resulted in a surface roughness similar to the DW at $50 \mathrm{~min}$. In the other times, Sorriso, Colgate and Corega caused more surface roughness than DW. In conclusion, specific dentifrices caused larger mass loss and lower surface roughness as conventional dentifrice.
\end{abstract}

Key Words: abrasiveness, toothbrushing, surface roughness, mass loss.

\section{INTRODUCTION}

Inadequate oral health of complete denture wearers has been widely documented $(1,2)$. Poor hygiene is associated with lack of proper orientation, denture anatomy, reduction of patients' dexterity, and inefficacy of denture cleansing products (3).

Complete denture biofilm is defined as a dense microbial layer formed by microorganisms and its metabolic products, being composed by more than $10^{11}$ microorganisms by gram in dry weight (4). Protected by the biofilm structure, microorganisms, especially Candida albicans, start the colonization of denture surface. The pathogenic biofilm can cause oral or systemic infections. Therefore, it is necessary an effective biofilm control with adequate denture cleansing because the adherence of microorganisms and residues are facilitated by irregular and rough surfaces, reducing the efficacy of the cleansing agent (5).
The ideal denture cleansing products must be ease to handle; effective on the removal of organic and inorganic deposits and stains; bactericidal and fungicidal; nontoxic to the patient; harmless to denture materials, and have low cost (6-8). Denture cleansing methods can be divided in two main groups: mechanical and chemical.

The mechanical methods are classified in brushing (with water, soap, dentifrice and abrasives) and ultrasonic devices (9). Brushing with dental brush and dentifrice or soap is the most diffused mechanical method. It has the advantage of being a simple method, low cost and effective in the removal of stains and organic deposits $(10,11)$. It has the disadvantages of difficulty of use, mainly for patients with motor coordination problems, possibility of surface damage to the acrylic resin and relines because of incorrect use $(12,13)$.

The magnitude of the abrasiveness by brushing depends on some factors: dentifrice abrasiveness, characteristics of the brush bristles, brushing technique

Correspondence: Profa. Dra. Helena de Freitas Oliveira Paranhos, Departamento de Materiais Dentários e Prótese, Faculdade de Odontologia de Ribeirão Preto, USP, Avenida do Café, S/N, 14040-904 Ribeirão Preto, SP, Brasil. Tel.: +55-16-3602-4031. e-mail: helenpar@forp.usp.br 
and frequency, strength applied on the brush and hardness of the brushed substrate (14-17).

The dentifrices are comprised of thickening agents, abrasives, humectants, surfactants, sweeteners and flavors (18). They enhance the action of the brush through its abrasive agents and detergents. Denture brushing with less abrasive or no dentifrice can result in the increasing of extrinsic stains on acrylic surface, but the worse effect of brushing with abrasive dentifrices is the wear of tooth structure and restorative and prosthetic materials (12). In vitro studies have tried to develop devices that can simulate actual brushing. Abrasion of denture acrylic resins is an important and undesirable phenomenon both aesthetically and biologically because it modifies acrylic surface conditions, making it rougher and more susceptible to stains and biofilm accumulation, and may also interfere in its adaptation (16).

In most cases, damages associated with dentifrice abrasiveness appear at long term and are considered by some authors as clinically insignificant. Sexson and Phillips (19) affirmed that after 2 years of manual brushing, it is estimated the loss of $1 / 3$ of millimeter of the surface of the denture base. A subject to be discussed is how much abrasive the cleanser agent need to be to promote an effective cleaning of a complete denture, as only the abrasiveness is usually studied, without associating with its capacity of clean $(20,21)$. Discussions about the relationship between cleansing efficacy and degree of abrasiveness have not been largely reported.

Acrylic resins have been used for the fabrication of complete dentures for over 60 years. They are composed of PMMA, a low hardness material that have the properties such as the abrasion resistance changed by different polymerization methods (22). Artificial acrylic teeth are also susceptible to abrasion when dentures are submitted to mechanical cleaning, possibly causing aesthetic problems for the denture (23).

The literature emphasizes the need of biofilm control with the establishment of proper cleansing protocols, emphasizing the importance of laboratory studies to know the action of each product (4).

Considering the period of replacement of complete dentures, knowing the resistance of the complete denture materials is of clinical interest for selection of more appropriate products and methods for the denture cleansing, without significant damages to the surface of denture base materials and artificial teeth. This study analyzed the mass loss and roughness caused in Plexiglass specimens by dentifrices (conventional and specific for denture cleansing).

\section{MATERIAL AND METHODS}

Three conventional dentifrices largely used in Brazil, and two specific dentifrices for complete dentures were evaluated. The materials are presented in Table 1.

\section{Specimen Preparation}

Thirty-six rectangular specimens $(90 \times 30 \times 4$ $\mathrm{mm}$ ) were fabricated from a polymethyl methacrylate plate (Plexiglass; Day Brasil S.A., Ribeirão Preto, SP, Brazil). The plastic used preparation of specimens is considered internationally acceptable for the analysis of dentifrice abrasiveness (22).

\section{Brushing Test}

The brushing test was carried out using a toothbrushing machine (Mavtec Comércio Ltda., Ribeirão Preto, SP, Brazil) in accordance with ISO/DTS 145692 specifications for wear testing (16). The machine allowed six specimens to be brushed simultaneously with a frequency of $356 \mathrm{rpm}$. The course covered by the brush corresponded to $3.8 \mathrm{~cm}$, and the load of the toothbrushing was standardized at $200 \mathrm{gf}$.

The 36 specimens, each identified with a number marking, were divided into 6 groups: control one $(n=6)$ with distilled water (DW) and the 5 experimental groups with suspensions of Sorriso $(n=6)$, Colgate $(n=6)$, Close Up $(n=6)$, Dentu Creme $(n=6)$ and Corega $(n=6)$ dentifrices. Before the brushing test, the specimens were immersed in DW to establish baseline values. Initial mass was measured in an Ohaus electronic balance accurate to $0.1 \mathrm{mg}$ and capacity of $210 \mathrm{~g}$ (Ohaus; Explorer, Pine Brook, NJ, USA) daily, until obtaining stable mass. Prior to weighing, the specimens were removed from the DW and dried with absorbent paper at room temperature.

The toothbrushes were cut at the neck and fixed by screws placed on the sides and the top of the support for the brush. The correct adjustment of these screws allowed the leveling of the appropriate brush. The type of toothbrush used in the present study (Table 1) had a rounded end, uniform length, flexibility, and 26 tufts of smooth bristles, with $0.25 \mathrm{~mm}$ in diameter and 10 mm of height.

Suspensions for brushing were prepared by 
mixing dentifrice and DW at room temperature at 1:1 ratio (90 g dentifrice and $90 \mathrm{~mL} \mathrm{DW}$ ), until the suspension was homogeneous). The control group was brushed with DW at $23 \pm 3^{\circ} \mathrm{C}$. The specimens in each group were submitted to the brushing test for 50, 100, 200 and $250 \mathrm{~min}(18,000,36,000,72,000$ and 90,000 cycles, respectively), calculated to correspond to 1,2 , 4 and 5 years of regular brushing by a healthy patient (20). Brushes and suspensions were replaced at 50-min intervals (22). After each brushing test, the specimens in each group were removed from the dentifrice suspension, washed, dried with absorbent paper and weighed, as follows: $\mathrm{pm} 1=\mathrm{m} 0-\mathrm{m} 1 ; \mathrm{pm} 2=\mathrm{m} 0-\mathrm{m} 2 ; \mathrm{pm} 3=\mathrm{m} 0-\mathrm{m} 3$; $\mathrm{pm} 4=\mathrm{m} 0-\mathrm{m} 4$, where, $\mathrm{m} 0$ is the initial mass and $\mathrm{m} 1$, $\mathrm{m} 2, \mathrm{~m} 3$ and $\mathrm{m} 4$ are the mass after 50, 100, 200 and 250 min of brushing.

\section{Surface Roughness Test}

Roughness of the Plexiglass specimens after brushing was measured using a roughness tester (Surftest SJ-201P; Mitutoyo Corp., Japan). Three measurements were made in the central area of each specimen, perpendicular to the brushing grooves at intervals of $5.0 \mathrm{~mm}$, and the average reading was designated as the roughness $(R a)$ value for that specimen after 50, 100, 200 and 250 min of toothbrushing. Baseline roughness measurements were not determined since all specimens were cut from Plexiglass plates, which are manufactured following industrial standards of high quality and uniformity. Mass loss and roughness data were subjected to ANOVA and Tukey's test at 5\% significance level.

\section{RESULTS}

Table 2 shows the results for mass loss. It was observed a trend of mass loss proportional to the testting time, except for DW, which maintained constant mass. In the initial period, the dentifrices caused greater mass loss than brushing with DW $(0.3 \pm 0.3)$. After $100 \mathrm{~min}$, the results were the same as those obtained for $50 \mathrm{~min}$. After $200 \mathrm{~min}$, the lowest mass loss was still for brushing with DW $(1.1 \pm 0.3)$, while the highest was obtained with Corega (29.0 \pm 3.0$)$, followed by Close Up (26.9 \pm 5.6 ). After $250 \mathrm{~min}$, the results were the same as for $200 \mathrm{~min}$. These results are illustrated in Figure 1.

Table 3 shows the results for roughness. DW had the same results over time, and did not take the changes close to null, as expected. Dentifrices produced similar roughness as DW at baseline and after $100 \mathrm{~min}$, after which time roughness increased. After $200 \mathrm{~min}$, all dentifrices caused more changes on surface roughness than DW. After 250 min of brushing, Sorriso (17.4 \pm 2.8 ) caused the greatest changes in surface roughness, and Dentu Creme $(10.4 \pm 3.0)$, the smallest ones. The other dentifrices presented intermediate outcomes. These results are illustrated in Figure 2.

\section{DISCUSSION}

The study of the abrasiveness of dentifrices on the denture base materials is important, since brushing is one of the most widely used methods by complete partial removable denture wearers $(3,4,9,10)$.

Measurement of mass loss is considered as

Table 1. Dentifrices and brush employed.

\begin{tabular}{lcc}
\hline Dentifrice/Brush & Abrasive particle & Manufacturer \\
\hline $\begin{array}{l}\text { Conventional dentifrices } \\
\text { Colgate Tripla Ação }\end{array}$ & Calcium carbonate, sodium bicarbonate & Colgate-Palmolive, Osasco, SP, Brazil \\
Sorriso Tripla Refrescância & Calcium carbonate, sodium bicarbonate & Colgate-Palmolive, Osasco, SP, Brazil \\
Close Up Red Hot & Silica & Unilever, Ipojuca, MG, Brazil \\
Specific dentifrices & & \\
Corega & Sodium bicarbonate, silica & Stafford Miller, Rio de Janeiro, RJ, Brazil \\
Dentu-Creme & Calcium carbonate & GlaxoSmithKline, Waterford, Ireland \\
Brush & & Johnson \& Johnson, São José dos Campos, SP, \\
Tek Soft & -- & Brazil \\
\hline
\end{tabular}


simple, adequate method to quantify the abrasion of acrylic resins by brushing $(20,21)$. In the present study, it was noticed a tendency of mass loss proportional to the brushing period, except for DW (control), which kept the mass constant (Table 2).

The results demonstrated that the specific dentifrice Corega caused more mass loss than the other dentifrices evaluated after 200 and $250 \mathrm{~min}$ of brushing. Another important factor to be pointed out is that at experimental periods (200 and $250 \mathrm{~min}$ ), Colgate and Sorriso, indicated for natural teeth, promoted less mass loss than Corega, and similar to Dentu Creme, which are both specific dentifrices for complete dentures.

The use of abrasive dentifrices causes wear of hard tissues, restorative and prosthetic materials (20-24). The deterioration of the finished and polished acrylic surface of removable dentures increase the risk of pigmentation due to the increase of surface roughness, and accumulation of biofilm, and can also compromise in denture fit and aesthetics (16).

The capacity of the tested dentifrices to abrade acrylic resin can be attributed to its abrasive components $(16,18)$, as calcium carbonate or calcium pyrophosphate. The concentration of abrasives, the different sizes and forms of the particles and the dilution of the dentifrices can explain the results obtained. Freitas et al. (20) pointed out that the brushing with DW caused little abrasion, but the combined effect of the brush with the dentifrice produced a significant abrasion. Some authors agree that abrasion occurs with less intensity with the increase of brushing time, although it never ceases (16). This fact

Table 2. Results for abrasiveness.

\begin{tabular}{lcccc}
\hline Treatment & $50 \mathrm{~min}$ & $100 \mathrm{~min}$ & $200 \mathrm{~min}$ & $250 \mathrm{~min}$ \\
\hline \multirow{2}{*}{ Water } & 0.3 & 0.7 & 1.1 & 2.3 \\
& $\pm 0.3 \mathrm{Ia}$ & $\pm 0.3 \mathrm{Ia}$ & $\pm 0.3 \mathrm{Ia}$ & $\pm 0.4 \mathrm{Ia}$ \\
\multirow{2}{*}{ Sorriso } & 6.1 & 11.6 & $23.0 \pm$ & $30.8 \pm$ \\
& $\pm 1.4 \mathrm{Ib}$ & $\pm 1.8 \mathrm{IIb}$ & $2.5 \mathrm{IIIb}$ & $2.6 \mathrm{IVb}$ \\
Colgate & 5.9 & 12.2 & $22.2 \pm$ & $30.9 \pm$ \\
& $\pm 1.2 \mathrm{Ib}$ & $\pm 1.3 \mathrm{IIb}$ & $0.8 \mathrm{IIIb}$ & $0.7 \mathrm{IVb}$ \\
Close Up & 6.2 & 12.5 & $26.9 \pm$ & $36.7 \pm$ \\
& $\pm 1.0 \mathrm{Ib}$ & $\pm 1.0 \mathrm{IIb}$ & $5.6 \mathrm{IIIbc}$ & $6.0 \mathrm{IVc}$ \\
Corega & 8.0 & 15.2 & $29.0 \pm$ & $39.2 \pm$ \\
& $\pm 0.7 \mathrm{Ib}$ & $\pm 1.6 \mathrm{IIb}$ & $3.0 \mathrm{IIIc}$ & $3.4 \mathrm{IVc}$ \\
Dentu Creme & 5.5 & 11.9 & $22.9 \pm$ & $30.6 \pm$ \\
& $\pm 0.7 \mathrm{Ib}$ & $\pm 1.4 \mathrm{IIb}$ & $1.9 \mathrm{IIIb}$ & $2.2 \mathrm{IVb}$ \\
\hline
\end{tabular}

$\overline{\text { Roman numerals indicate similarity among times and lowercase }}$ letters indicate similarity among treatments. can occur in in vitro experiments that do not change the dentifrice suspension regularly during the experiment, due to the precipitation of the abrasive particles in the course of time. In this study, such occurrence was not observed because the solutions and brushes were changed in intervals of $50 \mathrm{~min}$. Harrington et al. (25) replaced the brushes only when some deterioration and wear of bristles was observed, and Richmond et al. (16) and Haselden et al. (13) changed the brushes every 20,000 cycles, without referring to bristle wear.

The standardization of soft brushes used in this study permitted that the evaluation was exclusively of the tested dentifrices. The bristles of brushes have dimension of $0.25 \mathrm{~mm}$ of diameter and $10 \mathrm{~mm}$ of height, keeping the same hardness, degree of roughness and polishing. The rigidity of the bristles can influence in the abrasion of acrylic resins, as well in the loss of superficial brightness (17). The hardness degree of a toothbrush, the force applied during the brushing and its duration and frequency and dentifrice concentration are important factors in the determination of wear (14).

The abrasive particles present in dentifrices would be the real responsible for the damages to the prosthetic materials. These affirmations are in agreement with Dyer et al. (12), who verified that brushes of soft and flexible bristles combined with a dentifrice were more abrasive. Pisani et al. (22) comparing the abrasiveness of two specific dentifrices for complete dentures, Corega and Sorriso, concluded that there was no significant difference in mass loss between them, but the mass loss resulting from use of was significantly higher than that

Table 3. Results for surface roughness.

\begin{tabular}{lcccc}
\hline Treatment & $50 \mathrm{~min}$ & $100 \mathrm{~min}$ & $200 \mathrm{~min}$ & $250 \mathrm{~min}$ \\
\hline \multirow{2}{*}{ Water } & 0.0 & 0.0 & 0.0 & 0.0 \\
& $\pm 0.0 \mathrm{Ia}$ & $\pm 0.0 \mathrm{Ia}$ & $\pm 0.0 \mathrm{Ia}$ & $\pm 0.0 \mathrm{Ia}$ \\
\multirow{2}{*}{ Sorriso } & 1.5 & 3.7 & 12.2 & $17.4 \pm$ \\
& $\pm 0.7 \mathrm{Ia}$ & $\pm 1.2 \mathrm{Ia}$ & $\pm 3.7 \mathrm{IIb}$ & $2.8 \mathrm{IIc}$ \\
Colgate & 2.4 & 4.2 & 10.8 & $14.7 \pm$ \\
& $\pm 0.5 \mathrm{Ia}$ & $\pm 0.7 \mathrm{Ia}$ & $\pm 1.8 \mathrm{IIb}$ & $4.1 \mathrm{IIbc}$ \\
Close Up & 1.5 & $3.8 \pm$ & $8.8 \pm 6.6$ & $11.6 \pm$ \\
& $\pm 0.9 \mathrm{Ia}$ & $3.1 \mathrm{I} \mathrm{IIa}$ & $\mathrm{II} \mathrm{IIIb}$ & $7.5 \mathrm{IIIbc}$ \\
Corega & 0.7 & 1.6 & 9.3 & $13.1 \pm$ \\
& $\pm 0.7 \mathrm{Ia}$ & $\pm 1.5 \mathrm{Ia}$ & $\pm 3.0 \mathrm{IIb}$ & $3.3 \mathrm{IIbc}$ \\
Dentu Creme & 1.7 & 2.5 & $6.5 \pm$ & $10.4 \pm$ \\
& $\pm 1.3 \mathrm{Ia}$ & $\pm 2.0 \mathrm{Ia}$ & $2.6 \mathrm{I} \mathrm{IIb}$ & $3.0 \mathrm{IIb}$ \\
\hline
\end{tabular}

Roman numerals indicate similarity among times and lowercase letters indicate similarity among treatments. 
from the experimental dentifrices.

Like other studies $(17,18,20-22)$, another factor that was standardized in the present study was the brushing technique. The abrasion test was accomplished with constant speed and strength of the contact of the dentifrice with the specimens due to the use of an artificial brushing machine. The weight of the connector with the brush connected was $200 \mathrm{gf}$, though a stronger force can be applied depending of the user.

Sexson and Phillips (19) affirmed that the in vitro toothbrushing abrasion tests in artificial brushing machine is very strict, being difficult a comparison with the actual brushing by the patient. Even though this in vitro abrasiveness study cannot replicate the clinical situation, the test accomplished indicate the amount of abrasion that can be expected after a period of 5 years ( 90,000 cycles) of brushing of a removable denture.

In most in vitro toothbrushing abrasion tests, the brushing machines makes unidirectional, producing more irregularity in a same surface than it would actual occur in real life. So, this analysis has to be complemented by a quantitative analysis, like measurement of mass loss.

The surface roughness analysis showed that brushing with DW (control), in spite of taking to changes close to null as expect, did not modify with the time. At 100 and $200 \mathrm{~min}$, the dentifrices Sorriso and Colgate caused greater surface roughness than DW, whereas the dentifrice Dentu Creme presented smaller roughness, followed by Close Up and Corega respectively, after a brushing simulation for $200 \mathrm{~min}$. Thus, a smaller tendency to biofilm accumulation was observed in the dentures brushed with specific dentifrices. Times of 200 and 250 min presented statistically similar results.

Harrison et al. (15) observed that the grooves caused by the dentifrice Dentu Creme were smother and rounder in comparison to those produced by the dentifrice Colgate, which were more wrinkled in the groove base. The authors concluded that the dentifrices do not only have different abrasives, but also the shape of the particles used has different effects on surface finishing. The specific dentifrices, in spite of causing lower roughness, as well as Close Up, caused greater mass loss, which indicates that they are very abrasive (Table 3). As said above, these results can also be linked to the shape of the abrasive particles of each dentifrice.

The denture specified dentifrices and Close Up have particles that, in spite of resulting in greater abrasiveness, give a certain polish of the surface, instead of making it more rough. On the contrary, the conventional dentifrices Sorriso and Colgate cause less mass loss, but make the surface rougher.

This is a relevant result because one of the important requirements of a specific denture-cleansing dentifrice is having low abrasiveness to prevent acrylic resin wear (13,16). Pisani et al. (22) analyzed the surface roughness produced by two experimental dentifrices containing chloramine $T$ and Zonyl (Sorriso and Corega) and found that the difference between Corega and experimental dentifrices was not significant. Sorriso caused the greatest amount of surface roughness.

In conclusion, brushing with DW (control) did not cause significant mass loss or surface roughness change in the specimens. Dentifrices caused mass loss in all times. After 50 and 100 min of brushing, all dentifrices caused similar mass loss. At 200 and $250 \mathrm{~min}$, Close Up and Corega caused greater mass loss. Dentifrices caused significant changes on surface roughness only after 200 and $250 \mathrm{~min}$ of brushing. After $250 \mathrm{~min}$ of brushing, Sorriso caused the greatest changes on surface roughness.

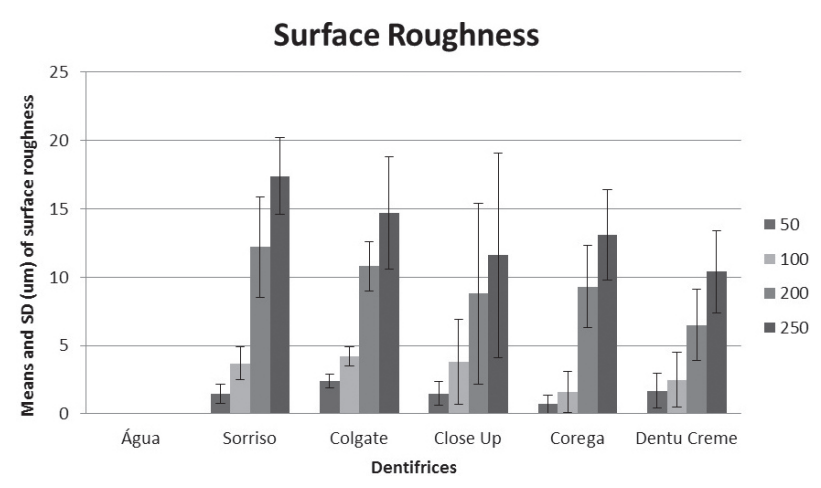

Figure 2. Means and standard deviation of surface roughness of specimens after brushing with the different dentifrices.
Figure 1. Means and standard deviation of mass loss of specimens after brushing with the different dentifrices.

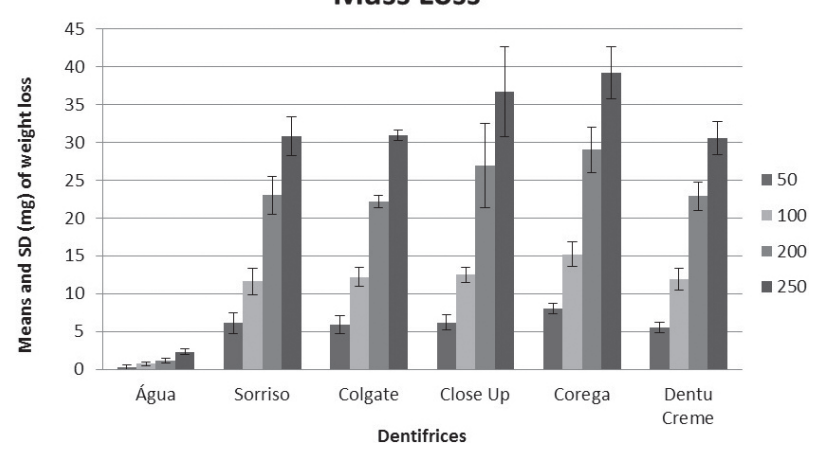

Braz Dent J 23(2) 2012 


\section{RESUMO}

Este estudo analisou a perda de massa e rugosidade superficial causadas em corpos de prova de Plexiglass por dentifrícios convencionais (Sorriso, Colgate e Close Up) e específicos (Corega e Dentu Creme) para higienização de próteses totais. Os corpos de prova de Plexiglass foram distribuidos em 6 grupos $(n=6)$, sendo um controle (água destilada - AD) e grupos experimentais. A escovação foi realizada em máquina de escovação com escovas macias e suspensões de dentifrícios ou $\mathrm{AD}$, de acordo com os diferentes tempos de escovação $(50,100,200$ e 250 min - 18.000, $36.000,72.000$ e 90.000 ciclos, respectivamente, calculados para corresponder a 1, 2, 4 e 5 anos de escovação regular). Os resultados de perda de massa e rugosidade superficial foram analisados por meio de ANOVA e teste de Tukey com 5\% de significância. Em todos os tempos analisados, a AD teve efeito insignificante. Os dentifrícios diferiram significativamente da AD no período inicial. O dentifrício Corega causou maior perda de massa em todos os tempos estudados, seguido por Close Up. No tempo de $50 \mathrm{~min}$, todos os dentifrícios causaram rugosidade superficial semelhante à $\mathrm{AD}$. Nos outros tempos, Sorriso, Colgate e Corega causaram maior rugosidade superficial em relação à $\mathrm{AD}$. Conclui-se que os dentifrícios específicos causaram maior perda de massa, porém menor rugosidade superficial que os dentifrícios convencionais.

\section{ACKNOWLEDGEMENTS}

The authors are grateful to FAPESP for the financial support (process \#2007/59221-5).

\section{REFERENCES}

1. Visschere LM, Grooten L, Theuniers G, Vanobbergen JN. Oral hygiene of elderly people in long-term care institutions - a crosssectional study. Gerodontology 2006;23:195-204.

2. Peracini A, Andrade IM, Paranhos Hde F, Silva CH, de Souza RF. Behaviors and hygiene habits of complete denture wearers. Braz Dent J 2010;21:247-252.

3. Felton D, Cooper L, Duqum I, Minsley G, Guckes A, Haug S, et al.. Evidence-based guidelines for the care and maintenance of complete dentures: a publication of the American College of Prosthodontists. J Prosthodont 2011;20:S1-S12.

4. Nikawa H, Hamada T, Yamashiro H, Kumagai H. A review of in vitro and in vivo methods to evaluate the efficacy of denture cleansers. Int J Prosthodont 1999;12:153-159.

5. Jagger DC, Al-Akhazam L, Harrison A, Rees JS. The effectiveness of seven denture cleansers on tea stain removal from PMMA acrylic resin. Int J Prosthodont 2002;15:549-552.

6. Paranhos HFO, Davi LR, Peracini A, Soares RB, Lovato $\mathrm{CH}$, Souza RF. Comparison of physical and mechanical properties of microwave-polymerized acrylic resin after disinfection in sodium hypochlorite solutions. Braz Dent J 2009;20:331-335.

7. Felipucci DN, Davi LR, Paranhos HF, Bezzon OL, Silva RF, Pagnano VO. Effect of different cleansers on the surface of removable partial denture. Braz Dent J 2011;22:392-397.

8. Cruz PC, Andrade IM, Peracini A, Souza-Gugelmin MC, SilvaLovato CH, de Souza RF, Paranhos Hde F. The effectiveness of chemical denture cleansers and ultrasonic device in biofilm removal from complete dentures J Appl Oral Sci 2011;19:668-673.
9. de Souza RF, de Freitas Oliveira Paranhos H, Lovato da Silva $\mathrm{CH}$, Abu-Naba'a L, Fedorowicz Z, Gurgan CA. Interventions for cleaning dentures in adults. Cochrane Database Syst Rev 2009:CD007395

10. Paranhos HFO, Silva-Lovato CH, Souza RF, Cruz PC, Freitas KM, Peracini A. Effects of mechanical and chemical methods on denture biofilm accumulation. J Oral Rehabil 2007;34:606-612.

11. de Andrade IM, Silva-Lovato CH, de Souza RF, Pisani MX, de Andrade KM, Paranhos Hde F. Trial of experimental toothpastes regarding quality for cleaning dentures Int $\mathrm{J}$ Prosthodont 2012;25:157-159.

12. Dyer D, MacDonald E, Newcombe RG, Scratcher C, Ley F, Addy M. Abrasion and stain removal by different manual toothbrushes and brush actions: studies in vitro. J Clin Periodontol 2001;28:121127.

13. Haselden CA, Hobkirk JA, Pearson GJ, Davies EH. A comparison between the wear resistance of three types of denture resin to three different dentifrices. J Oral Rehabil 1998;25:335-339.

14. Harte DB, Manly RS. Four variables affecting magnitude of dentrifice abrasiveness. J Dent Res 1976;55:322-327.

15. Harrison Z, Johnson A, Douglas CW. An in vitro study into the effect of a limited range of denture cleaners on surface roughness and removal of Candida albicans from conventional heat-cured acrylic resin denture base material. J Oral Rehabil 2004;31:460-467.

16. Richmond R, Macfarlane TV, McCord JF. An evaluation of the surface changes in PMMA biomaterial formulations as a result of toothbrush/dentifrice abrasion. Dent Mater 2004;20:124-132.

17. Teche FV, Paranhos HF, Motta MF, Zaniquelli O, Tirapelli C. Differences in abrasion capacity of four soft toothbrushes. Int J Dent Hyg 2011;9:274-278.

18. Panzeri H, Lara EH, Paranhos HFO, Lovato da Silva CH, de Souza $\mathrm{RF}$, de Souza Gugelmin MC, et al. In vitro and clinical evaluation of specific dentifrices for complete denture hygiene. Gerodontology 2009;26:26-33

19. Sexson JC, Phillips RW. Studies on the effects of abrasives on acrylic resins. J Prosthet Dent 1951;1:454-471.

20. Freitas KM, Paranhos HFO. Weight loss of five commercially available denture teeth after toothbrushing with three different dentifrices. J Appl Oral Sci 2006;14:242-246.

21. Freitas-Pontes KM, Silva-Lovato CH, Paranhos HF. Mass loss of four commercially available heat-polymerized acrylic resins after toothbrushing with three different dentifrices. J Appl Oral Sci. 2009;17:116-21.

22. Pisani MX, Bruhn JP, Paranhos HF, Silva-Lovato CH, de Souza RF, Panzeri H. Evaluation of the abrasiveness of dentifrices for complete dentures J Prosthodont 2010;19:369-373.

23. Machado AL, Giampaolo ET, Vergani CE, Pavarina AC, da Silva Lopes Salles D, Jorge JH. Weight loss and changes in surface roughness of denture base and reline materials after simulated toothbrushing in vitro [Epub ahead of print. DOI: 10.1111/j.17412358.2010.00422.x.]

24. Izumida FE, Ribeiro RC, Giampaolo ET, Machado AL, Pavarina AC, Vergani CE. Effect of microwave disinfection on the surface roughness of three denture base resins after tooth brushing. 2011;28:277-282

25. Harrington E, Jones PA, Fisher SE, Wilson HJ. Toothbrushdentifrice abrasion. A suggested standard method. Br Dent J 1982;153:135-138. 